\title{
COMPARAÇÃO ENTRE SECAGENS DE CAFÉ CEREJA DESCASCADO EM TERREIROS COM DIFERENTES TIPOS DE PAVIMENTAÇÃOO ${ }^{1}$
}

Fernando Ampessan², Adílio Flauzino de Lacerda Filho ${ }^{3}$, Marcus Bochi da Silva Volk ${ }^{4}$, Roberta Jimenez de Almeida Rigueira $^{5}$

\section{RESUMO}

Foi realizada a secagem de café cereja descascado em terreiro de asfalto e de concreto com objetivo de avaliar e comparar a influência do tipo de pavimentação no processo de secagem. Também foi avaliada a infecção por microrganismos e a eficiência energética. Para isso foram monitoradas as condições climáticas, temperaturas da massa de grãos, a intensidade de radiação solar sobre a superfície da massa de grãos, além da radiação refletida pelo café. O terreiro de asfalto apresentou maior rendimento de secagem, maior variação das temperaturas, menor taxa de reflexão de radiação solar, menor consumo específico de energia, menor contaminação por microrganismos e maior eficiência energética, em relação ao de concreto, para as mesmas condições ambientais. A classificação da bebida não apresentou diferença entre os tratamentos.

Palavras-chave: pós-colheita, qualidade, radiação solar.

\section{ANALYSIS OF COFFEE CHERRY DRYING ON DIFFERENT TYPES OF TERRACES}

\begin{abstract}
The study was done to evaluate and compare the influence of the terrace type on coffee cherry drying. The coffee was dried on asphalt or concrete terraces. Colonization by microorganisms and energy efficiency was analyzed. Weather conditions, grain mass temperature, the intensity of solar radiation on the surface of the grain mass and the radiation reflected by the cherries was also analyzed. Compared to the concrete terrace, the asphalt terrace had higher drying returns, greater temperature variation, lower reflection of solar radiation, lower specific energy consumption, less microbial contamination and higher energy efficiency. The brew quality of coffee dried on either terrace did not change.
\end{abstract}

Keywords: fter harvest, quality, solar radiation.

\section{Recebido para publicação em 22/06/2009. Aprovado em 16/03/2010}

1- Parte da Dissertação de Mestrado do primeiro autor, DEA-UFV; Av. PH. Rolfs s/n, CEP 36570 - 000, Viçosa, MG.

2- Mestre em Engenharia Agrícola da Universidade Federal de Viçosa. DEA-UFV. E-mail: fernando.ampessan@ufv.br

3- Professor Associado do Departamento de Engenharia Agrícola da Universidade Federal de Viçosa DEA-UFV. E-mail: alacerda@ufv.br

4- Doutorando do Programa de Pós- Graduação em Engenharia Agrícola da Universidade Federal de Viçosa. DEA - UFV. E-mail: marcus.volk@ufv.br

5- Pós- doutoranda pela FAPEMIG, Engenharia Agrícola da Universidade Federal de Viçosa. DEA-UFV. E-mail: roberta.rigueira@ufv.br 


\section{INTRODUÇ̃̃O}

O Brasil ocupa a posição de maior produtor e exportador de café no mercado internacional. A produção nacional de café na safra 2009 foi de mais de 39,5 milhões de sacas de 60 quilos de café beneficiado, sendo o Estado de Minas Gerais o maior produtor com mais de $50 \%$ dessa produção. (CONAB, 2009).

A qualidade do café depende da interação entre fatores que possibilitem preservar as características de sabor e aroma, atendendo aos padrões de qualidade. Podem existir cafés de qualidade inferior, originários de algumas regiões do Brasil,, em função de condições edafoclimáticas inapropriadas à produção, propícias ao desenvolvimento de microorganismos capazes de degradar a qualidade original dos frutos e grãos, além da falta de informação técnica e cuidados na colheita, beneficiamento, processamento e transporte. Os cafés despolpados e naturais ficam expostos a uma diversidade de microorganismos que produzem metabólitos, os quais agem sobre compostos químicos da mucilagem, principalmente sobre os açúcares. Quando as fermentações são prolongadas, a infecção por microrganismos torna-se acentuada e começa o processo de produção de compostos responsáveis pelos sabores indesejáveis. Esses fatores explicam a diferença na qualidade do café de uma região para a outra, pois, em locais de cafés de bebidas ruins, as condições climáticas, como alta umidade relativa e temperaturas elevadas, propiciam maior desenvolvimento de microrganismos (ALVES, 1996; CHALFOUN \& CARVALHO, 1997), depreciando a qualidade do produto. Os cuidados com as operações unitárias de pós-colheita são necessários para se obter café com qualidade.

A secagem artificial é uma dessas principais operações, por representar grande parte do custo operacional do sistema de produção e ser a operação que influencia diretamente a qualidade do produto. No Brasil, segundo os aspectos tecnológicos envolvidos, o café é secado em secadores mecânicos e em terreiros. O tempo de secagem e as taxas de redução de água são influenciados pelos diferentes procedimentos operacionais de secagem e processamento (CORADI, 2006; RIGUEIRA et al., 2007).

A secagem em terreiros consiste em espalhar os grãos sobre pisos de cimento, de tijolo, de chão batido ou de asfalto, com exposição direta à radiação solar global, e revolvê-los continuamente com o auxílio de rodo, ou de outro equipamento similar, a fim de homogeneizá-los e movimentá-los através do ar (SILVA \& BERBERT, 1999; LACERDA FILHO \& SILVA, 2006). É uma técnica muito utilizada pelos produtores brasileiros. Contudo, tal sistema apresenta alguns inconvenientes, estando, entre eles, a necessidade de grandes áreas para a sua construção, a excessiva mão de obra, a dependência das condições climáticas e da energia solar, como fonte de aquecimento para a consequente evaporação da água dos grãos (LACERDA FILHO, 1986; CAMPOS, 1998; SOUZA, 2000; CARDOSO SOBRINHO, 2001; REINATO et al., 2002; CORADI, 2006).

A secagem de café representa grande parte do custo operacional do sistema de produção e é a operação que mais influencia na depreciação ou valorização do produto. A secagem artificial em terreiro é, em algumas situações, mais onerosa quando comparada com a secagem realizada em secadores mecânicos, pois demanda muita mão de obra e expõe o produto às condições adversas de clima.

O alto teor inicial de água do café, entre 60 e $70 \%$ b.u, dificulta sua secagem, quando comparado ao de outros produtos, pois a velocidade de deterioração em sua primeira fase é maior, causando redução na qualidade do produto (SILVA et al., 1995; GUIMARÃES et al., 1998; DONZELES, 2002). A qualidade da secagem tem como base os teores de água, segundo o Instituto Brasileiro do Café - IBC, a faixa ideal de teor de água do café, depois de secado, varia entre 11 e $13 \%$ (b.u.) (SANTOS, 2005).

O tempo médio para secagem completa em terreiro é de 15 dias, nas condições do Sul de Minas, Alto Paranaíba e Triângulo Mineiro, e de 15 a 20 dias, na Zona da Mata de Minas Gerais (BÁRTHOLO \& GUIMARÃES, 1997). Normalmente, as safras dessas regiões podem coincidir com o período chuvoso, o que, juntamente, com o tempo necessário para a secagem, facilita o desenvolvimento de microrganismos e provoca fermentação e podridão na massa de grãos. Como consequência, tem-se uma bebida de qualidade inferior (LACERDA FILHO, 1986)

A secagem artificial em terreiro, além de requerer tempo relativamente longo, apresenta outras desvantagens, como: a utilização de grandes áreas nobres para a construção dos terreiros, a excessiva mão de obra e, muitas vezes, exposição do produto a condições climáticas adversas, o que pode favorecer o desenvolvimento de fungos e o processo de fermentação, que depreciam a qualidade do café 
(ROSSI \& ROA, 1980, LACERDA FILHO, 1986; CAMPOS, 1998; PALACIN, 2007).

Krug (1940) realçou a necessidade de estabelecer um processo de secagem mais rápido e eficiente, de maneira a proporcionar ao produto melhores qualidades organolépticas. Lacerda Filho (1986), em seus estudos sobre secagem de café em coco, em terreiros de diferentes materiais de pavimentação, encontrou, em média, eficiências energéticas de secagem de $15916,0 \mathrm{~kJ} \mathrm{~kg}^{-1}$, para piso de asfalto; $16996,5 \mathrm{~kJ} \mathrm{~kg}^{-1}$, para o de cimento; $16953,5 \mathrm{~kJ} \mathrm{~kg}^{-1}$ para o de tijolos e $17864,7 \mathrm{~kJ} \mathrm{~kg}^{-1}$, para o de terra batida, considerando as mesmas condições ambientais e o mesmo período. Donzeles (2002), utilizando secagem em terreiro de concreto, encontrou os valores de 14,36 e 18,05 $\mathrm{MJ} \mathrm{kg}^{-1}$ água para café cereja descascado, e de 12,36 e 13,13 $\mathrm{MJ} \mathrm{kg}^{-1}$ água, para o café cereja.

Taniwaki et al. (1998) analisaram amostras de café, provenientes de Minas Gerais, e isolaram Alternaria alternata, Fusarium incarnatum, Phoma sorghina, Penicillium aurantiogriseum e Aspergillus ochraceus. Taniwaki et al. (2003) isolaram e identificaram as espécies de fungos filamentosos, presentes em amostras de grãos de Cofffea arábica, provenientes de três regiões do Estado de São Paulo (Parapuã, Franca e Pirajú), nos estádios de cereja na árvore, cereja no chão, passas na árvore, passas no chão, terreiro e tulha. Os gêneros isolados foram Penicillium $s p$, Fusarium $s p$, Aspergillus niger e Aspergillus ochraceus. Alves \& Castro (1998) isolaram fungos presentes nas fases de maturação (verde-cana, cereja, passa e seco na planta), no chão e no beneficiamento de cafés cultivados, na cidade de Lavras, Minas Gerais. Identificaram Colletotrichum $s p$, Phoma sp, Cercospora sp, Fusarium sp, Cladosporium sp, Penicillium $s p$ e Aspergillus $s p$. Colletotrichum sp e Phoma sp.

Neste trabalho teve-se como objetivo principal monitorar, avaliar e comparar a secagem de café em terreiro de asfalto e de concreto, a contaminação por microrganismos no pergaminho e nos grãos de café durante o processo de secagem, além de avaliar a eficiência energética dos diferentes materiais de pavimentação do terreiro.

\section{MATERIAIS E MÉTODOS}

Foram utilizados cafés da variedade Catuaí, provenientes da região de Viçosa - MG, e as instalações da Associação Regional dos Cafeicultores de Viçosa - ARCA, localizada no próprio município. A ARCA possui uma estrutura com $7000 \mathrm{~m}^{2}$ de terreiros e dois secadores de leito fixo, em leiras, com capacidade de $10000 \mathrm{~L}$ cada um.

\section{Tratamentos}

Foram realizados três tratamentos:

T1 - secagem completa, em terreiro com pavimentação de concreto, até atingir o teor de água entre 11 e $12 \%$ b.u.;

T2 - secagem completa, em terreiro com pavimentação de asfalto, até atingir o teor de água entre 11 e $12 \%$ b.u.;

T3 - testemunha - secagem completa, em terreiro de leito suspenso, até atingir o teor de água entre 11 e $12 \%$ b.u.;

\section{Manejo}

Foram retiradas amostras dos grãos, ao se iniciar e depois de concluída a secagem. Nos tratamentos T1, T2 e T3, o café foi transportado e espalhado em camadas finas, por meio de um carrinho espalhador, sobre os respectivos terreiros, e revolvido manualmente, em intervalos regulares de três horas, utilizando-se rodo raspador, durante o período de exposição ao sol. Às 15 horas, o café era amontoado em forma de leiras, no sentido de maior declividade do terreiro, e coberto com lona plástica forrada com uma camada de saco de juta, com a finalidade de promover melhor isolamento térmico e de evitar que a evaporação da água do café se condensasse junto à lona e viesse a molhar o produto. Às $9 \mathrm{~h}$ do dia seguinte, as leiras eram descobertas $\mathrm{e}$ removidas do local de pernoite, para permitir a secagem do piso e, em seguida o produto era novamente espalhado conforme as rotinas já descritas anteriormente, até que a massa de grãos atingisse o teor final de água próximo a $12 \%$ b.u.

\section{Sistema de aquisição de dados}

Para a avaliação da secagem nos terreiros suspenso, de pavimentação asfáltica e de concreto foram monitoradas a temperatura e a umidade relativa do ar, a velocidade do vento, a radiação incidente e a refletida sobre os grãos, as temperaturas da massa de grãos e as das superfícies dos terreiros, exposta à radiação solar e coberta pela massa de grãos. Para tanto, foi utilizado um datallogger modelo CR 1000, fabricado pela Campbell Scientific Inc., utilizando o software PC200W Datalloger Support, versão 3.3. O CR 1000 foi programado para realizar leituras dos sensores a cada 5 segundos, gerando valores médios por hora. O datalogger, juntamente com os sensores, foi instalado no local do experimento. 
Para medir a temperatura e a umidade relativa do ar utilizou-se um sensor modelo "HMP50 Temperature and Relative Humidity Sensor"; para a velocidade do vento foi utilizado um anemômetro modelo "RM Young Wind Sentry Wind Speed Sensor". A radiação refletida nos terreiros de pavimentação de asfalto e de concreto foi medida utilizando dois piranômetros modelo "LP02 Pyranometer", um para cada pavimentação, e um modelo "SP-LITE Pyranometer", para medir a radiação incidente, todos os sensores de fabricação da Campbell Scientific Inc.

As temperaturas da massa de grãos e das superfícies dos terreiros, expostas à radiação solar e coberta pela massa de grãos, foram medidas utilizando-se termopares tipo "T". As medições foram realizadas às 9,12 e $15 \mathrm{~h}$; nesses mesmos horários, foram coletadas amostras para a determinação de teor de água, conforme método oficial de estufa, com circulação forçada de ar a $105 \pm 3{ }^{\circ} \mathrm{C}$, durante $24 \mathrm{~h}$ (BRASIL, 1992). Foram realizadas três repetições por amostra, com massa de aproximadamente $40 \mathrm{~g}$ cada.

\section{Monitoramento da contaminação por microrganismos no pergaminho e nos grãos de café}

Foram coletadas amostras com $300 \mathrm{~g}$ de café, que foram submetidas à análise no Laboratório de Fitopatologia da Universidade Federal de Viçosa, para a detecção e identificação de fungos, de acordo as técnicas descritas por Dhingra e Sinclair (1996).

\section{Classificação do café}

As amostras retiradas de cada tratamento foram analisadas e classificadas, conforme o estabelecido pela Instrução Normativa $\mathrm{n}^{\circ} 8$, de 11/06/2003, publicada pelo Ministério da Agricultura, Pecuária e Abastecimento (MAPA), que estabeleceu o "Regulamento Técnico de Identidade e Qualidade para a classificação do café Beneficiado do Grão Cru" (BRASIL, 2003), pela Corretora Três Irmãos, que, por meio da prova de xícara forneceu notas relacionadas com a bebida dos cafés, em que:

acima de 90 - estritamente mole (EM);

de 80 a 90 - mole (M);

de 75 a 80 - apenas mole (AM);

abaixo de 74 - dura (D).

\section{RESULTADOS E DISCUSSÃO}

Na Figura 1, apresentam-se as curvas de secagem de café, em terreiro, com os diferentes pisos estudados. Verifica-se que o terreiro com piso de asfalto apresentou maior rendimento de secagem, considerando as mesmas condições ambientais, mesmo teor inicial de água e o mesmo intervalo de tempo. No terreiro de asfalto, o café foi secado até teor de água de $11,49 \%$ b.u., enquanto, no terreiro suspenso, atingiu-se $13,56 \%$ b.u. e, no de concreto, $16,55 \%$ b.u.

Observa-se, também, que a chuva ocorrida durante a noite do $6^{\circ}$ para o $7^{\circ}$ dia influenciou diferentemente o teor de água do café nos três

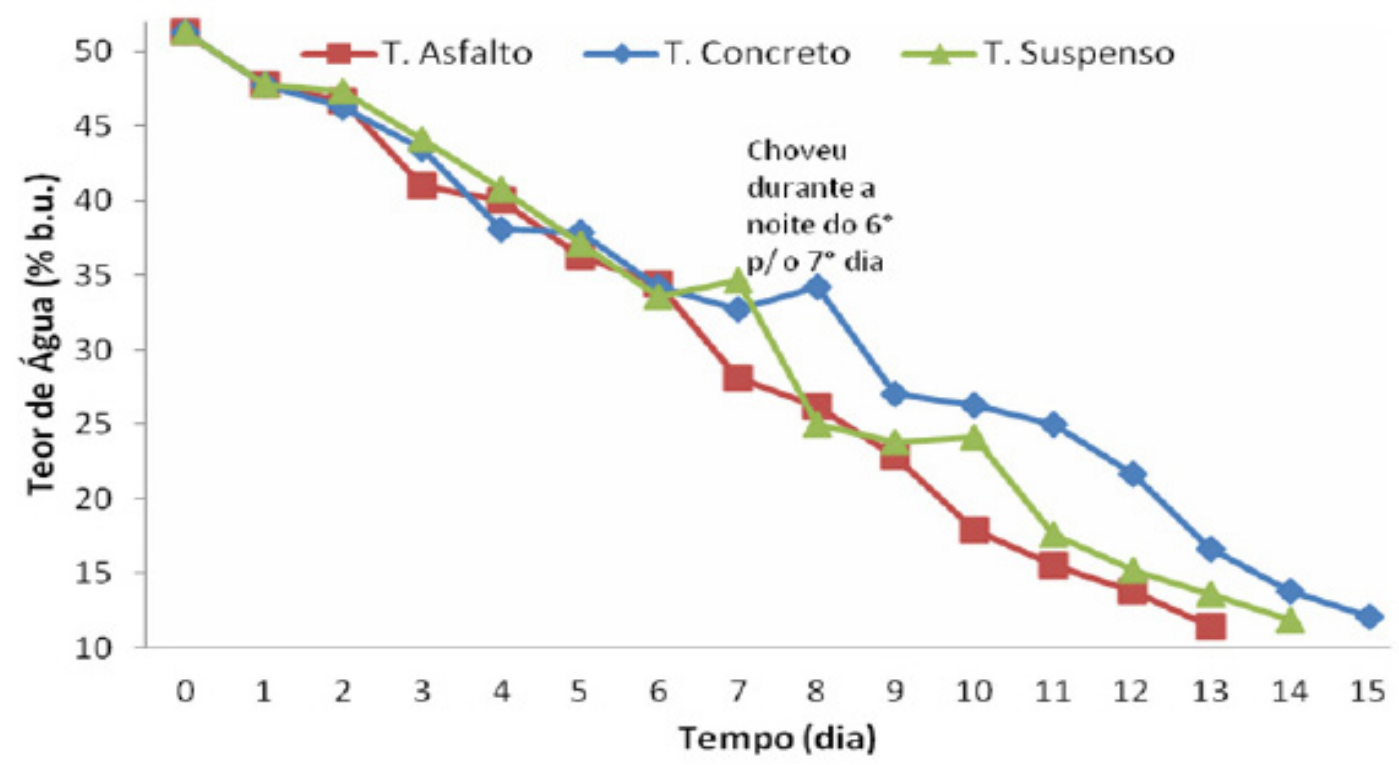

Figura 1. Curvas de secagem do café quando submetido a diferentes formas de secagem. 
tratamentos. No terreiro de asfalto, não houve alteração na curva de secagem, pelo fato de o piso ser impermeável, ao contrário do terreiro de concreto, em que se observou elevação do teor de água depois do período de chuva, justificada por causa da sua permeabilidade. O terreiro suspenso apresentou outro comportamento, uma vez que a variação do teor de água dos grãos está diretamente relacionada com a umidade relativa do ar, apresentando elevação no teor de água, evidenciada durante o período chuvoso.

Verifica-se na Figura 2, que, à medida que o teor de água diminui, houve aumento na temperatura da massa de grãos, em relação à temperatura ambiente. A partir do $6^{\circ}$ dia até o final da secagem, o teor de água dos grãos no terreiro de asfalto foi menor do que no terreiro de concreto, justificando a maior temperatura alcançada pela massa de grãos do terreiro de asfalto a partir deste momento.

$\mathrm{O}$ terreiro de asfalto apresentou maior variação no que se refere à temperatura, em relação ao terreiro de concreto, tanto para a superfície exposta à radiação solar direta, $\left(6,96{ }^{\circ} \mathrm{C}\right)$, quanto na superfície coberta pela massa de grãos, $\left(6,30^{\circ} \mathrm{C}\right)$. O terreiro de concreto apresentou variação de $5,36^{\circ} \mathrm{C}$, para a superfície exposta à radiação solar direta, e de $5,98{ }^{\circ} \mathrm{C}$, na superfície coberta pela massa de grãos, o que contribuiu para a diminuição no tempo de secagem no terreiro de asfalto, em relação ao de concreto (Figuras 3 e 4).

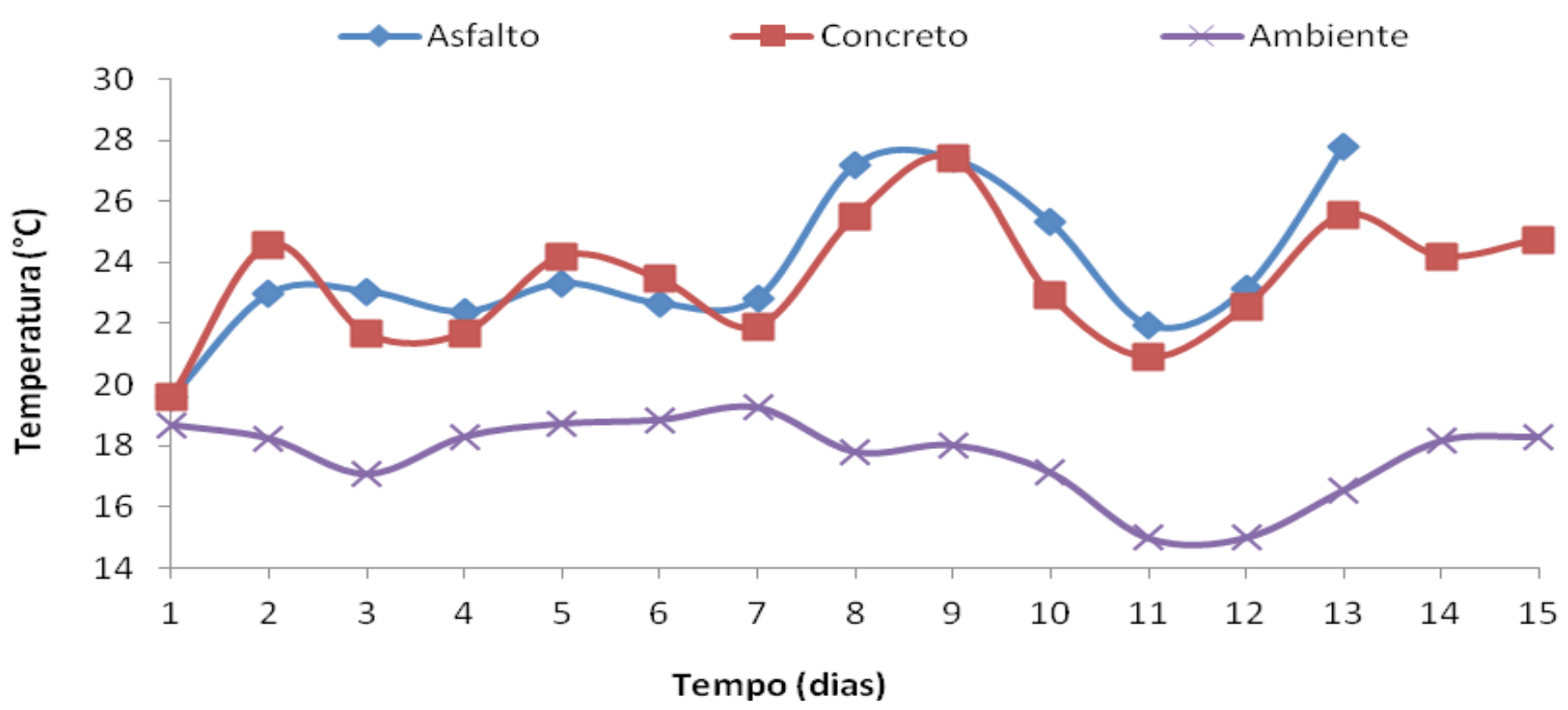

Figura 2. Variações entre as temperaturas dos grãos, quando submetido a diferentes formas de secagem, e ambiente.

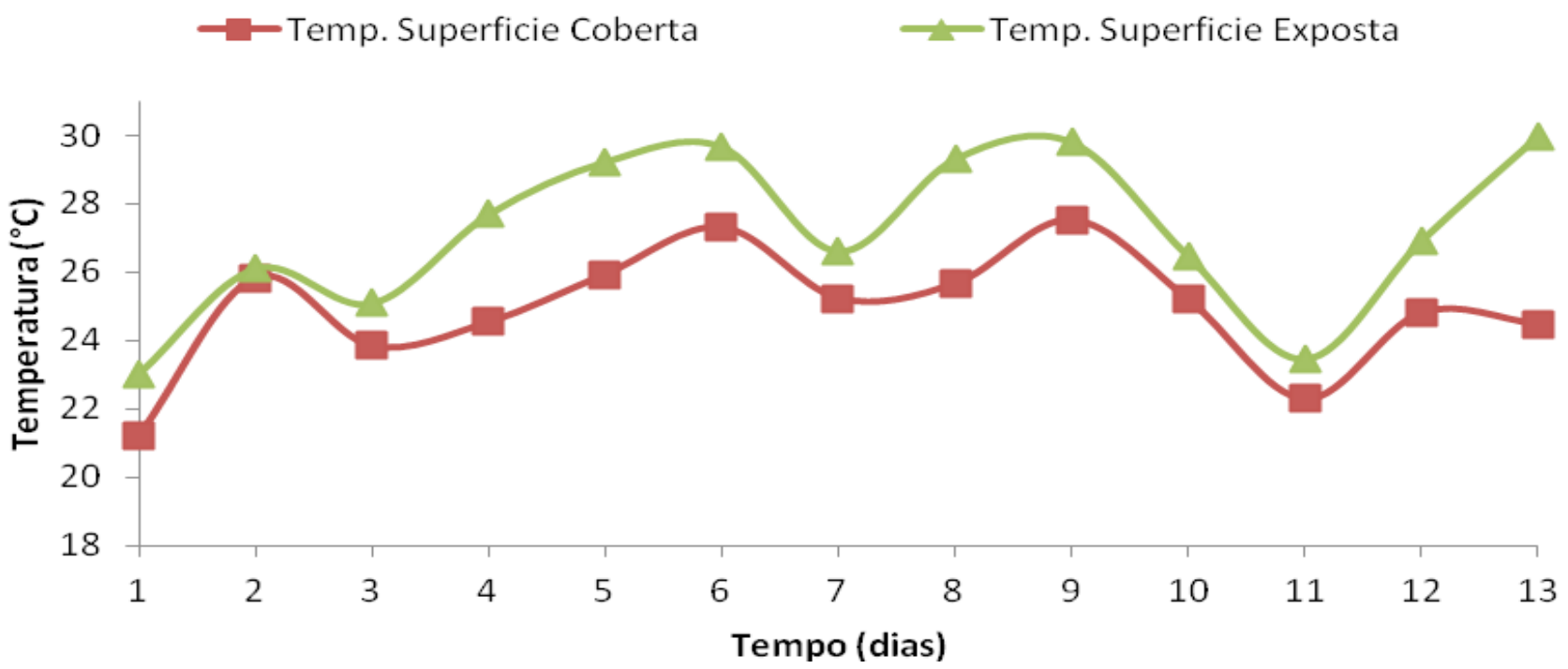

Figura 3. Variações nas temperaturas dos grãos, quando a superfície foi coberta e quando ficaram expostos, em terreiro de asfalto (T1). 


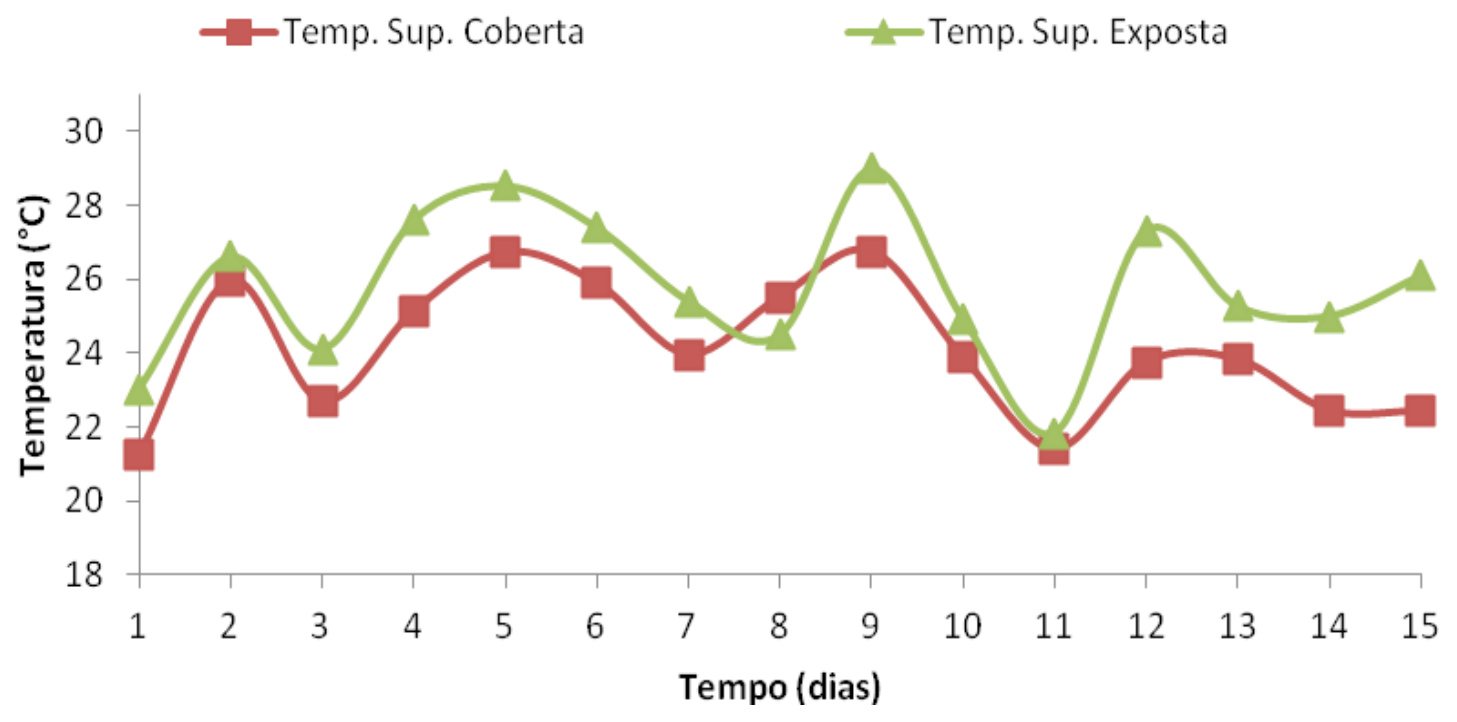

Figura 4. Variações entre as temperaturas dos grãos, quando a superfície foi coberta e quando ficaram expostos, em terreiro de concreto (T2).

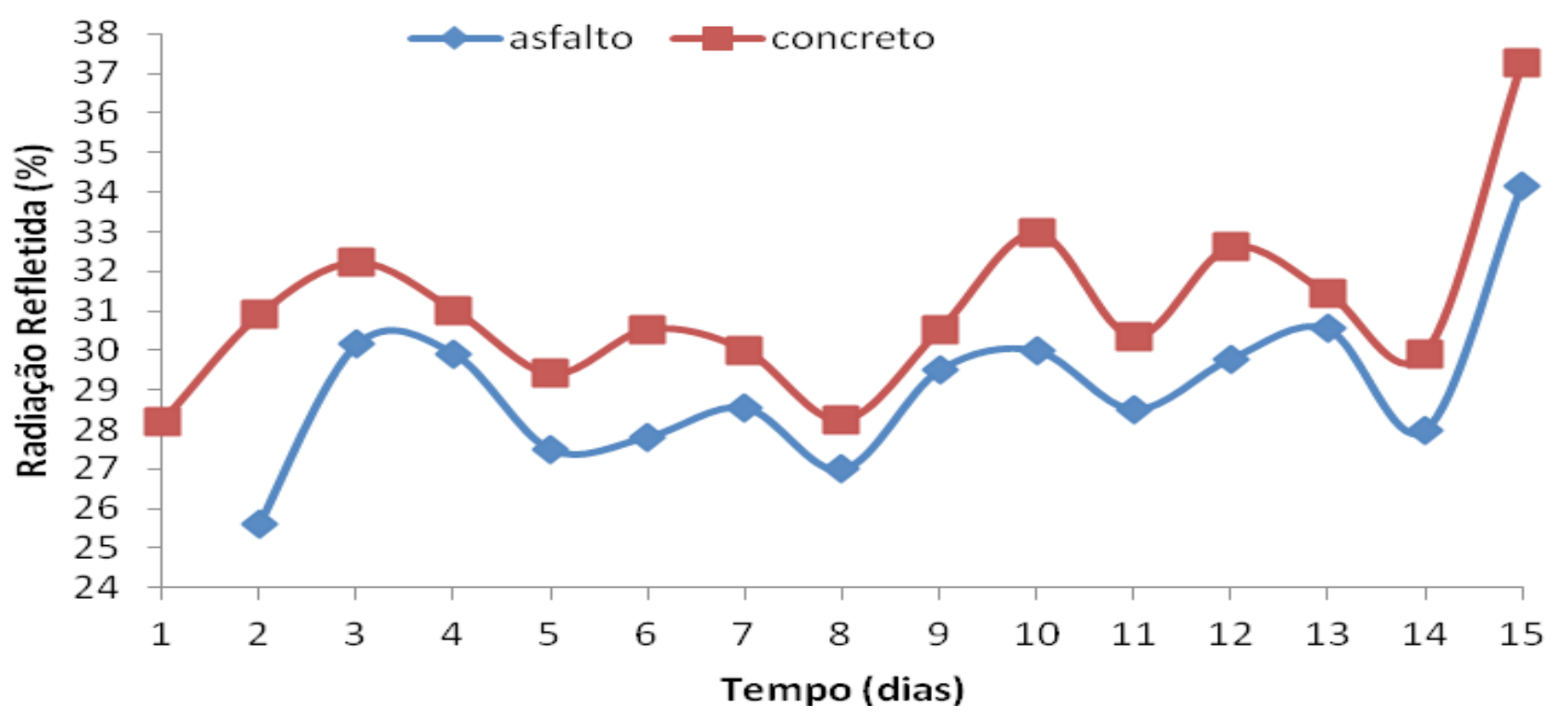

Figura 5. Variação percentual da luz solar refletida nos terreiros.

O terreiro de asfalto também apresentou maiores valores de temperatura dos grãos que o de concreto, sendo $27,52{ }^{\circ} \mathrm{C}$, na superfície coberta pela massa de grãos, e $29,98{ }^{\circ} \mathrm{C}$, na superfície exposta à radiação solar direta, enquanto, no terreiro de concreto, os valores foram, respectivamente, de $26,75^{\circ} \mathrm{C}$ e $29,0^{\circ} \mathrm{C}$.

Apresenta-se na Figura 5 a variação percentual de reflexão da radiação solar, incidente nos terreiros de concreto e de asfalto, durante a secagem. A reflexão da radiação solar foi maior no terreiro de concreto, durante todo o período de secagem, em relação ao terreiro de asfalto. $\mathrm{O}$ terreiro de concreto refletiu em média $30,22 \%$ da radiação solar incidente e, o de asfalto $27,77 \%$.

Com o auxílio dos dados apresentados no Quadro 1, observa-se que o tipo de piso teve influência sobre a eficiência de secagem. O consumo específico de energia foi menor para o terreiro de asfalto, aproximadamente $11,10 \%$, em relação ao de concreto.

A contaminação fúngica foi maior no terreiro de concreto em relação ao de asfalto; isto pode ser observado no Quadro 2, e ocorreu pelo fato de o terreiro de concreto ficar exposto, por maior tempo, a fatores favoráveis ao desenvolvimento de microrganismos, como: teor de água da massa de grãos; temperatura e umidade relativa do ar.

A contaminação fúngica no tratamento $\mathrm{T} 3$, testemunha, foi menor do que nos submetidos ao T1 e T2, visto que, no terreiro suspenso, a massa de grãos está exposta à 
Quadro 1. Consumo específico de energia dos terreiros de asfalto e concreto

\begin{tabular}{cccc}
\hline Terreiro & $\begin{array}{c}\text { Massa de Água } \\
\text { Evaporada } \\
(\mathrm{kg})\end{array}$ & $\begin{array}{c}\text { Energia } \\
\text { Consumida } \\
(\mathrm{MJ})\end{array}$ & $\begin{array}{c}\text { Consumo Específico } \\
\text { de Energia } \\
\left(\mathrm{MJ} / \mathrm{kg} \mathrm{H}_{2} \text { O evap.) }\right.\end{array}$ \\
\hline Asfal to & 112,36 & 1063,37 & 9,4640 \\
Concreto & 111,48 & 1186,88 & 10,6462 \\
\hline
\end{tabular}

Quadro 2. Resultados percentuais da análise fúngica em café submetido a diferentes tratamentos de secagem

\begin{tabular}{|c|c|c|c|c|c|c|c|}
\hline (\%) & & Acremonism & $\begin{array}{c}\text { Fusarü } \\
\text { me }\end{array}$ & $\begin{array}{c}\text { Cladosporum } \\
\text { sp. }\end{array}$ & $\begin{array}{c}\text { Phoma } \\
\text { sp. }\end{array}$ & $\begin{array}{l}\text { Aspergilluss } \\
\text { glaucus }\end{array}$ & $\begin{array}{l}\text { Aspergilles } \\
\text { ochraceus }\end{array}$ \\
\hline $\begin{array}{c}\text { Amostra } \\
\text { Inicial }\end{array}$ & c/ perg. & 23 & 23 & 2 & 1 & & \\
\hline Inicial & s/ pere & 14 & 14 & & & & \\
\hline T1 - Terreiro & c/ perg. & 23 & 23 & 11 & 20 & 4 & \\
\hline Asfalto & $s /$ perg. & 9 & 9 & & & 1 & 1 \\
\hline T2 - Terreiro & c/ pere. & 31 & 31 & 6 & 19 & 24 & \\
\hline Concreto & $s /$ perg. & 29 & 29 & 1 & 2 & 8 & \\
\hline T3-Terreiro & c/perg. & 19 & 19 & 3 & 12 & & \\
\hline Suspenso & s/ pere & 19 & 19 & & 3 & & \\
\hline
\end{tabular}

Quadro 3. Resultado da classificação de bebida, conforme normativa $n^{\circ} 8$

\begin{tabular}{lcccc}
\hline \multicolumn{1}{c}{ Amostra } & & T1 & T2 & T3 \\
\hline Rendimento & $(\%)$ & 74,00 & 75,67 & 74,67 \\
Teor de Água & $(\%)$ & 11,49 & 12,05 & 11,92 \\
MK12* & $(\%)$ & 2,00 & 5,00 & 3,00 \\
18 & $(\%)$ & 17,00 & 29,00 & 23,00 \\
MK11* & $(\%)$ & 8,00 & 9,00 & 7,00 \\
17 & $(\%)$ & 28,00 & 26,00 & 30,00 \\
16 & $(\%)$ & 27,00 & 21,00 & 25,00 \\
MK 10* & $(\%)$ & 4,00 & 6,00 & 5,00 \\
15 & $(\%)$ & 6,00 & 8,00 & 5,00 \\
FUNDO & $(\%)$ & 8,00 & 5,00 & 2,00 \\
CATA & $(\%)$ & 3,00 & 6,00 & 8,00 \\
DEFEITO & & 27,00 & 39,00 & 60,00 \\
\hline BEBIDA & & 79 (Apenas Mole) & 77 (Apenas Mole) & 79 (Apenas Mole) \\
\hline
\end{tabular}

* peneiras com furo oblongo - tipo moca

circulação de ar todo o tempo, inclusive no período noturno.

Aclassificação da bebida não apresentou diferença entre os tratamentos, como pode ser observado no Quadro 3.

\section{CONCLUSÕES}

Para as condições experimentais é possível concluir que:

- A secagem do café cereja descascado em terreiro com pavimentação de asfalto é mais rápida do que no terreiro com pavimentação de concreto;

- As características do material de pavimentação do terreiro não proporcionam elevadas diferenças de temperatura na massa de café durante a secagem; 
- A secagem utilizando terreiro com pavimentação de asfalto apresentou maior eficiência energética, em comparação com o terreiro de concreto, para as condições experimentais;

- Há redução na incidência de fungos conforme reduz-se o teor de água dos grãos, indiferentemente do material de pavimentação do piso de terreiro;

- Não houve influência do tipo de terreiro sobre a qualidade da bebida do café, conforme evidenciado na prova da xícara.

\section{AGRADECIMENTOS}

À Illycaffé, à "Coordenação de Aperfeiçoamento de Pessoal de Nível Superior" (CAPES), à Universidade Federal de Viçosa e ao Departamento de Engenharia Agrícola, pelo apoio na realização deste trabalho.

\section{REFERÊNCIAS}

ALVES, E. População fúngica associada ao café (Coffea arabica L.) beneficiado e as fases pré e pós colheita relação com a bebida e local de cultivo. 1996. 48 f. Dissertação (Mestrado em .... ) - UFLA, ,Lavras. 1996.

BÁRTHOLO, G.F.; GUIMARÃES, P.T.G. Cuidados na colheita e preparo do café. Informe Agropecuário, Belo Horizonte, v.18, n.187, p.33-42, 1997.

BRASIL. Ministério da Agricultura, Pecuária e Abastecimento. Regulamento técnico de identidade e de qualidade para a classificação do café beneficiado grão cru. Instrução Normativa $n^{-}$ 8, de 11 de junho de 2003. 2003. 11 p.

BRASIL. Regras para Análise de Sementes. Ministério da Agricultura e Reforma Agrária. Secretaria Nacional de Defesa Agropecuária. Brasília: MAA/DNDV, 1992. 365 p.

CAMPOS, A.T. Desenvolvimento e análise de um protótipo de secador de camada fixa para café (Coffea arabica L.), com sistema de revolvimento mecânico. 1998. 61 f. Dissertação (Mestrado em Engenharia Agrícola) - Universidade Federal de Viçosa, Viçosa-MG: 1998.

CARDOSO SOBRINHO, J. Simulação e avaliação de sistemas de secagem de café. 2001. ... f. Dissertação (Mestrado em Engenharia Agrícola) Universidade Federal de Viçosa,.Viçosa-MG. 2001.

CHALFOUN, S.M.; CARVALHO, V.D. Efeito de Microorganismos na qualidade da bebida do café. Informe agropecuário, Belo Horizonte, v.18, p.2126, 1997.

CONAB, Companhia Nacional de Abastecimento. Acompanhamento da Safra Brasileira Café Safra 2009, quarta estimativa, dezembro/2009 - Brasília: 2008.

CORADI, P.C. Alterações na qualidade do café cereja natural e despolpado submetidos a diferentes condições de secagem e armazenamento. 2006. 75 f. Dissertação (Mestrado em Engenharia Agrícola). Universidade Federal de Lavras Lavras, MG.2006..

DONZELES, S.M.L. Desenvolvimento e avaliação de um sistema híbrido, solar e biomassa, para secagem de café (Coffea arabica L.). 2002. 122 f. Tese (Doutorado em ...) - Universidade Federal de Viçosa, Viçosa. 2002.

GUIMARÃES, A.C.; BERBERT, P.A.; SILVA, J.S. Ambienta ir drying of pré-trated coffee (Coffea arabica L.). Jornal of Agricultural Engenering Research, v. 69, p. 53-62, 1998.

KRUG, H. P. Cafés duros II um estudo sobre a qualidade dos cafés de varrição. Revista do Instituto do Café, São Paulo, v. 27, p. 1393-1396, set. 1940.

LACERDA FILHO, A.F. de. Avaliação de diferentes sistemas de secagem e suas influências na qualidade do café (Coffea arabica L.). 1986. 136 f. Dissertação (Mestrado em ...).- Universidade Federal de Viçosa, Viçosa. 1986

LACERDA FILHO, A.F. de; SILVA, J.S. Secagem de café em combinação. Revista Brasileira de Engenharia Agrícola e Ambiental, Campina Grande, PB, DEAg/UFCG -v.10, n.3, p.671-678, 2006.

LACERDA FILHO, A.F. de; SILVA, J.S. Secagem de café em combinação. Revista Brasileira de Engenharia Agrícola e Ambiental, Campina Grande, 
PB, DEAg/UFCG -v.10, n.3, p.671-678, 2006.

PALACIN, J.J.F., Avaliações energética e econômica de sistemas de produção de café de montanha. 2007. 282 f. Tese (Doutorado em ....) Universidade Federal de Viçosa, Viçosa. 2007. UFV.

REINATO, H. R., BORÉM, F. M., VILELA, R., CARVALHO, MEIRELES, P. Consumo de energia e custo de secagem de café cereja em propriedades agrícolas do sul de Minas Gerais. Revista Brasileira de Engenharia Agrícola e Ambiental, Campina Grande, v.6, n.1, p.112-116, 2002.

RIGUEIRA, R.J.de A.; LACERDA FILHO, A.F. de; SILVA, J.S.; CECON, P.R.; PALACIN, J.J.F. Caracterização da Qualidade do Café (coffea arabica 1.) Submetido a Diferentes Condições de Secagem e Armazenagem. Engenharia na Agricultura, Viçosa, MG, v.15, n.2, 151-167, Abr./Jun., 2007.

ROSSI, S.J.; ROA, G. Secagem e armazenamento de produtos agropecuários com uso de energia solar e ar natural. São Paulo: Academia de Ciências do Estado de São Paulo, 1980. 295 p.

SANTOS, M.A. Influência do preparo por via úmida e tipos de secagem sobre a composição física, fisico química e química do café Coffea arabica L. 2005. 60 f. Dissertação (Mestrado em Ciências dos Alimentos) - Universidade Federal de
Lavras, Lavras.2005.

SILVA, J.S.; AFONSO, A.D.L.; LACERDA FILHO, A.F. Secagem a armazenagem de produtos agrícolas. In: SILVA, J.S. Pré-processamento de produtos agrícolas. Juiz de Fora, MG: Instituto Maria, 1995. p. $395-461$.

SILVA, J.S.; BERBERT, P.A. Colheita, secagem e armazenagem de café. Viçosa, MG: Aprenda Fácil, 1999. 146p.

SOUZA, S. M. C. Secagem de café com qualidade. III-Secagem. Circular Técnica, Lavras, [s.n.], Jun. 2000. n.119, 4p.

TANIWAKI, M.H.; BANHE, A.A.; IAMANAKA, B.T. Fungos produtores de ocratoxina em café. In: ENCONTRO NACIONAL DE MICOTOXINAS, 9., 1998; SIMPÓSIO EM ARMAZENAGEM QUALITATIVA DE GRÃOS DO MERCOSUL, 1., 1998, Florianópolis. Livro de resumos... Florianópolis: UFSC/Dep. Ciência e Tecnologia de Alimentos/Centro de Ciências Agrárias; Sociedade Latino-Americana de Micotoxicologia, 1998. p. 107.

TANIWAKI, M.H.; IAMANAKA, B.T.; VICENTINI, M.C. Fungos produtores de ocratoxina e ocratoxina A em cafés. Disponível em: $\quad$ http://www.coffeebreak.com.br/ocafezal. asp?SE=8\&ID=119 Acesso em : 31 jan. 2009. 